\title{
Multi-aspect impact of eco-innovations ("sustainable goods") as a form of development of innovative potential of the region
}

\author{
Asiya Khasanova $^{1, *}$, Elena Dotsenko ${ }^{1}$, Natalya Ezdina ${ }^{1}$, and Magdi Khasanov ${ }^{2}$ \\ ${ }^{1}$ Plekhanov Russian University of Economics, 117997, Moscow, Russia \\ ${ }^{2} \mathrm{M}$. V. Lomonosov MSU, Moscow, Russia
}

\begin{abstract}
The article considers spatial distribution of innovations as one of the forms of implementation of the mechanism of their evolution, which leads to the formation of "centers" and "peripheries" of the innovation potential of the national economy. The paper takes into account the features of the spatial organization of the economy, formed as a result of the allocation and reallocation of assets under the influence of competition processes, which are reflected in neoclassical theories of economic growth.
\end{abstract}

\section{Introduction}

Recently, globalization and integration of national innovation processes are features of the innovative model of economic growth of the leading countries of the world economy, due to the complexity of ensuring technological breakthroughs that guarantee the conquest of new world markets. The priority is to " deepen the integration of regional educational and scientific infrastructures by strengthening links between research institutes, academic institutions and enterprises; stimulating the creation of an "academic innovation belt", which should consist of enterprises that introduce scientific developments into production; increasing the number of enterprises that introduce innovations by providing " local preferences "(incentives initiated by local authorities), strengthening the innovation and modernization component of privatization processes, and introducing a system of regional innovation priorities; introduction of "innovativeness" as one of the main statistical criteria for assessing regional development, as well as the practice of periodic statistical reports on indicators of regional innovative development; assistance in the development and implementation of regional innovation policy programs based on the experience of leading regions, etc."a

\section{Materials and methods}

The analysis of alternative theories of innovation allows us to conclude that their provisions are complementary and to propose an integrative dynamic multi-level

${ }^{a}$ Sustainable development of enterprise, region, society: innovative approaches to security: monograph / under the General editorship of Dr. Econ. Sciences, Professor O. V. Prokopenko. - Poland: "Drukarnia i

StudioGraficzneOmnidium", 2014. - 474 p. approach that interprets the innovation process using the principles of process and system approaches. In the framework of the diachronic approach, we proceed from the recognition of spatial variability, which provides wave diffusion of innovations along and beyond the axes of development. In this regard, it is possible to use the provisions of the theory of stochastic processes to develop simulation models of innovation propagation.

Within a homogeneous space, local spatial formations are formed - territorial production complexes, the functioning of which is analyzed using balance models. Within the framework of a structured space, diverse "centers" and "peripheral areas" arise, the interaction between which is described using theories of innovation propagation.

Table 1 shows the indicators of the level of innovation activity of industrial production organizations and the service sector. The data show an insufficient level of innovative development of the Russian Federation subjects.

For the period 2014-2018 in the Russian Federation as a whole, the indicator of innovation activity of organizations engaged in technological marketing and organizational innovations varies between 9.5-10.4\%, and the share of organizations implementing technological innovations was $7.9-9.2 \%$. $^{\mathrm{b}}$

However, the main factor influencing the development of innovation is resource availability (table 2). The analysis of indicators showed a fairly stable positive dynamics of resource support for innovative development.

In accordance with the provisions of an integrated theory of regional development, the ambivalence of development of economic space that manifests the

\footnotetext{
${ }^{\mathrm{b}}$ regions of Russia. Socio-economic indicators-2018

[Electronic resource] access Mode:

http://www.gks.ru/bgd/regl/b18_14p/Main.htm
} 
Table 1. Dynamics of the indicator of the level of innovation activity of organizations in Federal districts, in $\%$ of the total number of surveyed organizations*.

\begin{tabular}{|c|c|c|c|c|c|c|c|c|c|c|}
\hline & \multicolumn{5}{|c|}{$\begin{array}{l}\text { Technological marketing and organizational } \\
\text { innovations }\end{array}$} & \multicolumn{5}{|c|}{ Technological innovations } \\
\hline & 2014 & 2015 & 2016 & 2017 & $2018^{*}$ & 2014 & 2015 & 2016 & 2017 & $2018^{*}$ \\
\hline Russian Federation & 9,5 & 10,4 & 10,3 & 10,1 & 10,2 & 7,9 & 8,9 & 9,1 & 8,9 & 9,0 \\
\hline Central Federal distric & 8,6 & 10,2 & 10,9 & 10,7 & 10,7 & 7,3 & 8,8 & 9,7 & 9,6 & 9,7 \\
\hline North-West Federal district & 9,4 & 11,2 & 11,0 & 10,7 & 10,8 & 7,6 & 9,5 & 9,5 & 9,2 & 9,3 \\
\hline South FD & 7,5 & 6,5 & 7,4 & 7,2 & 7,2 & 6,2 & 5,3 & 6,3 & 6,2 & 6,3 \\
\hline North-Caucasus FD & 6,2 & 5,2 & 6,4 & 5,9 & 6,1 & 5,0 & 4,2 & 5,6 & 5,3 & 5,4 \\
\hline Volga FD & 12,3 & 12,7 & 11,9 & 11,7 & 11,8 & 10,2 & 11,2 & 10,8 & 10,4 & 10,6 \\
\hline Ural FD & 11,5 & 11,5 & 10,6 & 9,6 & 9,8 & 9,6 & 9,8 & 9,0 & 8,0 & 8,1 \\
\hline Siberian FD & 8,2 & 8,8 & 8,5 & 9,1 & 9,3 & 6,8 & 7,6 & 7,7 & 8,2 & 8,4 \\
\hline Far Eastern FD & 8,6 & 11,2 & 10,8 & 9,5 & 9,7 & 7,0 & 9,6 & 9,6 & 8,3 & 8,7 \\
\hline
\end{tabular}

Table 2. Expenditure on technological innovation organizations (by Federal districts), mln. RUB *.

\begin{tabular}{|l|r|r|r|r|r|}
\hline & \multicolumn{1}{|c|}{2014} & \multicolumn{1}{|c|}{2015} & \multicolumn{1}{|c|}{2016} & \multicolumn{1}{c|}{2017} & \multicolumn{1}{c|}{$2018^{*}$} \\
\hline Russian Federation & 1211897,098 & 1203638,084 & 1284590,331 & 1404985,291 & 1536664 \\
\hline Central Federal distric & 377883,2687 & 411465,8535 & 528154,6818 & 457472,1492 & 396249 \\
\hline North-West Federal district & 92916,6189 & 87877,5628 & 115306,5477 & 142733,8438 & 176685,1 \\
\hline South FD & 67365,6685 & 70070,0633 & 66255,5575 & 82662,5821 & 103132,5 \\
\hline North-Caucasus FD & 9746,0611 & 5909,1405 & 7896,4821 & 8956,8298 & 10159,56 \\
\hline Volga FD & 331308,1683 & 300124,4748 & 258847,1437 & 336919,0124 & 438538,4 \\
\hline Ural FD & 122952,692 & 120131,4035 & 153891,1892 & 186288,6629 & 225506,5 \\
\hline Siberian FD & 150313,8541 & 140231,7926 & 97864,0179 & 131370,4486 & 176348,7 \\
\hline Far Eastern FD & 59152,414 & 67230,9894 & 56374,711 & 58581,7624 & 60875,22 \\
\hline$*$ - by rating & \multicolumn{5}{|l}{} \\
\hline
\end{tabular}

discrepancy between the phases of the development cycles of space assets and space of innovation, namely, the upward phase of the cycle space of innovations initiated at the exponential phase, the medium-term economic cycle, when the growth of the aggregates is proportional to the number of used factors of production.

The innovation cycle is a form of implementation of implicit laws of innovation processes, including the transition from research and development to commercialization of intellectual activity results, experimental and mass production.

The link between the traditional medium-term cycle (asset cycle) and the innovation cycle is realized through the processes of innovation propagation, which can take the form of direct and indirect diffusions.

The nature of interaction between two cyclical processes changes at different stages of their development. The degree of stability and time lags of transitions are determined by the state of the institutional environment and the effectiveness of control actions.

While recognizing the traditional roles of centers and peripheral areas as donors and recipients of innovation, it is worth noting the differences in the latter's ability to perceive innovations, as well as the function of semiperiphery in their retransmission. The characteristics of the periphery and semi-periphery determine the level of investment attractiveness of the owners of production factors and their placement space. ${ }^{\mathrm{c}}$

\footnotetext{
${ }^{\mathrm{c}}$ Ecologization of Regional Industrial Complex in the $\underline{\text { Transition to Sustainable }}$
}

The analysis carried out in this work allowed us to clarify the criteria for turning industries into leading sectors of the economy, namely: the presence of basic technological innovations that are at the growth stage; the production of investment products by subjects of this sector and competition with substitute technologies.

Thus, the theory of diffusion of innovations has been developed in recognition of the role of urbanised territories in which agglomeration effect is realized; the diffusion of innovation along the axis of development from metropolises to the periphery reduces the amount of external effect and does not provide with the need for the formation of a vicious cycle of innovation and effective regional innovation system; the position about the role of aggregate demand, stimulated by government at the regional level, as the factor of innovative development.

In response to the growing demands of a society that needs products manufactured in accordance with the principles of ethics and social responsibility, modern multinational and local companies have to make public statements about the desire for full control of the supply chain. In particular, TNCs are increasingly required to minimize their environmental impact across the chain by reflecting their commitment in procurement decisions. Thus, sustainable procurement is a process in which

Development 04050/Elena Dotsenko, Natalia Ezdina and Svetlana Mudrova-Published online: 26 June 2018 DOI: https://doi.org/10.1051/e3sconf/20184104050pdf $\underline{(234 \mathrm{~kb})} \backslash \underline{\text { references }}$ nasa ads abstract service 
organizations purchase raw materials and supplies, taking into account the following factors: the overall life cycle of the product; environmental aspects - for example, the use of secondary raw materials and $\mathrm{CO} 2$ emissions; and social aspects, including human rights, labor rights, and fair trade. ${ }^{\mathrm{d}}$

From a business perspective, it makes sense to include sustainable purchasing and supply decisions in the triple criteria concept.

\section{Results and discussions}

Under the influence of multinational corporations, suppliers of raw materials and other resources try to integrate sustainable development issues into a comprehensive internal procurement policy, or so-called supplier code of conduct. ${ }^{\mathrm{e}}$

Sustainable development can be a source of opportunity, innovation, and even competitive advantage. Some companies go even further and make sustainable purchases the centerpiece of their value proposition for customers. In Russia, corporate decisions to expand agricultural support programs aimed at small farmers and other suppliers are primarily driven by management's stated commitment to implementing sustainable development principles throughout the supply chain.

Depending on their business logic, some companies focus on minimizing the environmental footprint at the product recycling stage. For example, one of these initiatives by Toyota is aimed at the safe disposal of used cars in Russia. This is the only Russian sector where the amount of emissions, accounting for $3 \%$ of total greenhouse gas emissions in Russia, currently exceeds the level of 19907. Solid waste management in Russia is poorly developed: only $3-4 \%$ of the total output is processed. Optimization of waste management technologies will reduce the level of waste-related emissions by $80 \%$. Through recycling, it is possible "to reduce annual emissions by 33 metric tons by 2030, indirectly saving about 6 metric tons of carbon equivalent energy per year." $\mathrm{f}$

\footnotetext{
${ }^{\mathrm{d}}$ Implementation of environmental principles of sustainable development in the mining region Shavina, E., Prokofev, V. E3S Web of

Conferences, 2020, 174, 02014

e McKinsey \& Company (2009 г.).Pathways to an Energy and Carbon Efficient Russia. Opportunities to Increase Energy Efficiency and Reduce Greenhouse Gas Emissions // Режим доступа

свободный.http://www.mckinsey.com/ /media/mckinse $\mathrm{y} /$ dotcom/client_service/sustainability/ cost $\% 20$ curve $\% 20$ pdfs/russian_cost_curve_summary_en glish.ashx

${ }^{\mathrm{f}}$ Sustainable development in Russia: guide for multinational companies. // Institute for emerging markets research, SKOLKOVO business school. Access mode is free.

http://amr.ru/files/\%D0\%9A\%D0\%A1\%D0\%9E/\%D0\% A1\%D0\%9A\%D0\%9E\%D0\%9B\%D0\%9A\%D0\%9E\%
}

According to experts, negative environmental consequences may cause world food prices to rise by 30$50 \%$ in the coming decades and increase the instability of prices for all natural raw materials, which will sharply worsen the situation of the poor. "The greatest risks are expected to be 1.3 billion people engaged in agriculture, forestry, fishing, hunting and other areas of nature management".g

The green economy is becoming a new engine of growth, contributing to the creation of decent jobs and is a vital factor in eliminating chronic poverty, refuting the stereotype of the inevitable contradiction between environmental sustainability and economic progress. There is also a need for serious institutional changes at the regional, national and supranational levels in order to improve human well-being, while preserving the planet's resources and not exposing future generations to significant environmental risks, i.e. towards the transition to a "green economy". i

\section{Conclusion}

Thus, "sustainable goods" or eco-innovations are considered as an independent form of innovation, the need for which is determined by the presence of negative external effects of the functioning of urbanized territories. At the same time, it is necessary to consider eco-innovations in relation to technological innovations in the context of sustainable development, which implies an increase in economic, social and environmental costs. At the same time, eco-innovations are considered as a condition for obtaining an increment of environmental value, i.e. a factor of sustainable development. The formation of an innovative ecosystem is considered as a necessary condition for the competitiveness of business structures and the territory where they are located.

D0\%92\%D0\%9E \%D0\%A0\%D1\%83\%D0\%BA\%D0\% BE\%D0\%B2\%D0\%BE\%D0\%B4\%D1\%81\%D1\%82\%D 0\%B2\%D0\%BE\%20\%D0\%B4\%D0\%BB\%D1\%8F\%20 $\% \mathrm{D} 1 \% 82 \% \mathrm{D} 1 \% 80 \% \mathrm{D} 0 \% \mathrm{~B} 0 \% \mathrm{D} 0 \% \mathrm{BD} \% \mathrm{D} 1 \% 81 \% \mathrm{D} 0 \%$ BD\%D0\%B0\%D1\%86\%D0\%B8\%D0\%BE\%D0\%BD\% D0\%B0\%D0\%BB\%D1\%8C\%D0\%BD\%D1\%8B\%D1\% $85 \% 20 \% \mathrm{D} 0 \% \mathrm{BA} \% \mathrm{D} 0 \% \mathrm{BE} \% \mathrm{D} 0 \% \mathrm{BC} \% \mathrm{D} 0 \% \mathrm{BF} \% \mathrm{D} 0 \%$ B0\%D0\%BD\%D0\%B8\%D0\%B9 2016.pdf checked 25.02.2019.

g Towards sustainable development in Russia: Green economy and modernization / / Bulletin Of the Institute for sustainable development of the Public chamber of the Russian Federation, 2012, no. 60.

${ }^{\mathrm{h}}$ Ecologization of Regional Industrial Complex in the Transition to Sustainable

Development 04050/Elena Dotsenko, Natalia Ezdina and Svetlana Mudrova-Published online: 26 June 2018 DOI: https://doi.org/10.1051/e3sconf/20184104050pdf $\underline{(234 \mathrm{~kb}) \backslash \text { references nasa ads abstract service }}$

${ }^{i}$ Sustainable development of enterprise, region, society: innovative approaches to security: monograph / under the General editorship of Dr. Econ. Sciences, Professor O. V. Prokopenko. - Poland: "Drukarnia i StudioGraficzneOmnidium", 2014. - 474 p. 


\section{References}

1. O. V. Prokopenko, Sustainable development of enterprise, region, society: innovative approaches to security, 474 (drukarnia I studiograficzneomnidium, 2014)

2. McKinsey Companies (2009). Ways to energy and efficient carbon management in Russia. Opportunities for improving energy efficiency and reducing greenhouse gas emissions

3. Towards sustainable development in Russia: Green economy and modernization, Bulletin Of the Institute for sustainable development of the Public chamber of the Russian Federation, 60 (2012).

4. Blaugm. Clark, Johnbates, 100 great economists of Keynes = Great economists before Keynes: an introduction to the life and work of one Hundred great economists of the past, 134-137, 352 (SPb. Ekonomikus, 2008).

5. N. Amirova, L. Sargina, A. Khasanova, Natural resource potential as a factor in the formation of the natural and economic system of the region, E3S Web of Conferences, 174, 02011 (2020)

6. N.R. Amirova, L.V. Sargina, A.S. Frolova, Development of the ecological trend in the modern market of goods and services, CITISE, 5, 277-291 (2019).

DOI: http://doi.org/10.15350/24097616.2019.5.25

7. E. Dotsenko, N. Ezdina, Structural problems of innovative development of the mining region (Kuzbass, Western Siberia), E3S Web of Conferences, 15 (2017).

https://doi.org/10.1051/e3sconf/20171504012

8. Elena Dotsenko, Natalia Ezdina and Svetlana Mudrova, Greening of the regional industrial complex in the context of transition to sustainable development E3S Web of Conferences, 04050, (2018), https://doi.org/10.1051/e3sconf/20184104050pdf $(234 \mathrm{~KB}) \backslash$ links to the nasa ads abstract service

9. N. Ezdina, Humanity and the environment interact in the shadow of technological convergence, E3S Web of Conferences, 21 (2017) https://doi.org/10.1051/e3sconf/20172104015

10. E. Shavina, V. Prokofiev, Implementation of environmental principles of sustainable development in the mining region, E3S Web of Conferences, 174, 02014 (2020)

11. R. Nurkse, Problems of capital formation in underdeveloped countries (Oxford, 1953)

12. P. Rosenstein-Rodan, Notes on the "big push " Theory, Economic development for Latin America, 60 (New York, 1961)

13. W.W. Rostow, Transition to self-Sustaining growth.Economy of backwardness. (London, 1960).

14. V.V. Shlychkov, A.S. Khasanova, I. K. Kiyamov, S.M. Kulish, V.R. Nestulaeva, Practical management: theoretical and methodological approaches and Russian practice of state and municipal management, European Research Studies Journal, 20(2), 200-223 (2017)

15. E. Shavina, V. Prokofiev, Implementation of environmental principles of sustainable development in the mining region, E3S Web of Conferences, 174, 02014 (2020). 